is in Europe, due to lack of language teaching facilities at secondary school, hardly made good by perfunctory courses in French, English and so on for scientists at university level; and secondly, it often appears easier for an African scientist to arrange study leave and research facilities in Europe or North America than in a neighbouring African country. Comparative approaches, in consequence, are rare, and good local case studies tend to remain local in their impact. But above all, the major difficulty lies in the nature of the work, straddling the divide between social and natural sciencean unfortunate line of demarcation hallowed not by logic but by usage.

Leaving aside the arid socialantisocial, natural-supernatural science arguments, there are genuine differences of style and method between social and natural scientists-social scientists, for example, are part of what they study and their language leans towards the polemical in the hope of influencing their material for good. Such differences have to be overcome before the two groups can work together effectively. And yet ethnobotany, 'folk' medicine and 'appropriate' technology would be unthinkable without collaboration between, say, biochemists, ecologists, agronomists and engineers on the one hand and linguists, ethnographers and geographers on the other.

The Environmental Review Unit of the International African Institute is one body trying to find its way across these various barriers and obstacles, partly through its bilingual publications programme, which is based on a working relationship between the
Training for the Environment Programme in Dakar and the IAI (the journal African Environment/Environment Africain and the Special Report series of monographs and collections of essays are joint ventures, for example), and partly through a research programme which emphasises the involvement of African scientists and scholars in cross-national studies of environmental problems from a comparative and interdisciplinary point of view. The IAI's traditional strength lies in the linguistic and social science fields, but this is being complemented by links with institutions in Africa having strong natural science representation.

Three major research projects are in the course of being established. The first involves the study of nutritional concepts and strategies in subsistence societies and how these are changing, for better or for worse, under the impact of agricultural development. The second is in a way linked, being an attempt by a group of archaeologists, ethnobotanists and ethnographers to investigate the origins as well as the present-day significance of yam cultivation in Africa. The third project involves looking at the agronomic and ecological conceptions of peasant farmers to assess the role they might play in community-based programmes of environmental monitoring and resource management in Africa; it is based on collaboration between IAI research workers in Africa and the Monitoring and Assessment Research Centre of Chelsea College. London, with initial funding from SCOPE, and has resulted in a preliminary report of a Nigerian case study.
The funding of such research, which falls between the natural and the social sciences, poses problems of its own. But with initial results exhibiting great promise for further development along the lines outlined, the hope is that those who normally fund research on either the social or the natural science side will stretch their terms of reference to cover this vital area. The financial resources required are relatively modest but, even so, no single institution or individual can assemble and effectively combine the range of skill and experience required. Inter-disciplinary cooperation rather than intellectual rivalry is the essential pre-requisite. World wide studies by the Disaster Research Unit at the University of Bradford indicate that, while the probability of the occurrence of geophysical and climate disturbances has remained constant over the last hundred years, 'disasters' have doubled.

The conclusion is plain-namely that human communities are increasingly vulnerable to natural hazard, for social rather than natural reasons. Players of the environmental game appear to have two strategies open to them-minimising maximum losses or maximising potential gains. The modern world opts for the latter in the interests of growth and profit. But someone has to pay the price for this aggressive competitiveness, and it is the poor who end up more vulnerable to ecological breakdown than ever before. Good environmental research is difficult to do because it requires a direct reversal of precisely those qualities of individual rivalry and competitiveness that lie at the root of our present environmental predicament.

\title{
US BUDGET
}

\section{Escaping the 'New Realism'}

\section{Colin Norman explains how science and technology fare}

W HEN President Ford unveiled his election year Budget last week, he said it reflected "New Realism" in government policy in the United States. The new realism turned out, however, to be old-style conservatism in the shape of proposals for massive increases in military spending, swingeing cuts in government expenditure in fields such as health and social services, and tax relief for individuals and corporations. Many of those proposals will be unpalatable to the democratic-controlled Congress - which must act on them before they become law-and thus, as a guide to what will actually be spent by government departments and agencies in the 1977 fiscal year (which begins on October 1, 1976), Mr Ford's budget figures should be treated with considerable caution.

Nevertheless, the budget, which consists of thousands of pages of facts and figures, richly laced with promises and rhetoric, is an important statement of the Administration's political thinking; it sets out in fine detail the programmes for which Mr Ford and his Administration will seek congressional approval in the coming months. As far as science and technology are concerned, the Administration's thinking seems to be surprisingly expansive in view of the frugality displayed elsewhere in the budget.

The extensive axe-wielding which resulted in keeping the total budget. request within $\mathrm{Mr}$ Ford's target of

\section{Sorry, for copyright reasons some images on this page may not be available online}

\section{Gerald Ford: 'realist'}

$\$ 395,000$ million for the federal government next year, left most areas of research and development relatively unscathed. In fact, Mr Ford has proposed hefty increases in several areas 
of science and technology, though there are notable exceptions in a few areas, such as biomedical research and space science.

Putting the figures in their best possible light, Dr H. Guyford Stever, the President's science adviser and Director of the National Science Foundation (NSF), noted last week that the budget contains a total of $\$ 23,500$ million for research and development and a further $\$ 1,200$ million for scientific equipment and facilities. If Congress agrees to the figures, and if all the money is spent, that would amount to an increase of some $\$ 2,200$ million $(11 \%)$ over anticipated expenditures this year. With inflation now reckoned to be about 6 or $7 \%$, the budget proposals would actually result in some real growth in federal support for science and technology.

The increases are particularly unexpected because federal expenditures on research and development fall almost entirely in the portion of the budget which is relatively controllable. More than half the total budget is now spent on such items as pensions and medical payouts for the poor and elderly, which cannot easily be cut, and thus Mr Ford had to look for most of his savings in the relatively controllable section. Using a bit of the rhetoric which is customary on such occasions, Dr Stever told reporters last week that the fact that science and technology fared well in the budget suggests that "this Administration has clearly placed a high priority on research and development for the achievement of national goals".

Two of the Administration's goalsbeefing up military technology and securing long-term energy independence for the United States-would swallow up the lion's share of the increases. But another, more surprising trend emerges from the budget pro- posals. Basic research, federal support for which has dwindled since the late 1960 s, would get a monetary shot in the arm, increasing by about $11 \%$. The National Science Foundation's research budget alone is set for an increase of about $20 \%$, and anticipated support for research and development in colleges and universities is set for a $9 \%$ boost.

Within that overall budget, the Administration has decided to give its backing to a number of large new science projects. There is money in the budget to begin construction of a $\$ 78$ million positron-electron colliding beam device at Stanford University, NASA has been given the green light to begin building a solar spacecraft to study the maximum sunspot activity in 1979-80, and several new energy projects have been proposed.

But there are also bleak spots. Congress and the Administration have not yet been able to agree on the size of the budget for the National Institutes of Health (NIH) for this year, let alone next year, and a lengthy tussle seems inevitable. Ford, in short, wants to trim this year's budget for NIH below what it was in 1975, and he has proposed only a modest increase above the 1975 budget for 1977 (see later). Congress on the other hand, wants to increase the NIH budget substantially. The outcome of that tussle will profoundly affect the entire picture for support of research and development by the federal government, particularly in the universities which receive nearly half their total funds for federal research from NIH. Furthermore, NASA has had to defer plans for several key science projects, including the large space telescope, and the Environmental Protection Agency's research and development budget has suffered from the Administration's knife.

Another area which is troubling many government science agencies is that $\mathrm{Mr}$ Ford wants to cut the size of the civil service, which means that although some agencies may get larger research budgets, they will have to administer them with fewer people.

How is Congress likely to treat the science budget? Traditionally, the Administration's budget request is picked over piecemeal by a number of appropriations subcommittees, each of which handles the budget for one or two departments or agencies. Consequently, it has been difficult for Congress to keep track of the size of the total budget, and it has not been easy for Congress to set priorities for some departments in relation to others. But this year, for the first time, Congress has a fully operational budget system to combat those deficiencies. A Budget Committee will establish an overall target figure for the entire federal budget (which may or may not be the same as Mr Ford's target figure), and it will set limits for each individual appropriations subcommittee to stick to. Though the Budget Committee is likely to sympathise with $\mathrm{Mr}$ Ford's attempt to reduce the size of the federal deficit-the Administration's budget anticipates that the deficit will shrink from $\$ 76,000$ million this year to $\$ 43,000$ million next-it will probably attempt to do it in a different way. In short, the major budget battles are likely to centre on the size of the defence budget, with Congress seeking to reduce it below Mr Ford's proposed level, and the size of the budget for the Department of Health, Education and Welfare, which Congress will try to increase. Since those two departments fund the bulk of federal research and development, the outcome of those battles will shape the overall picture for science and technology.

The following are the major highlights in the budget for science and

Table 1 Conduct of research and development of major departments and agencies (in $\$$ million)

Department or agency

Defence--Military functions

National Aeronautical and Space Administration

Energy Research and Development Administration

Health, Education, and Welfare

National Science Foundation

Agriculture

Transportation

Interior

Environmental Protection Agency

Commerce

Veterans Administration

Nuclear Regulatory Commission

Housing and Urban Development

Justice

All other

Total

Total, conduct of research
Total, conduct of development

Total, conduct of research
Total, conduct of development

\begin{tabular}{r}
1975 \\
actual \\
8,987 \\
3,088 \\
2,071 \\
2,395 \\
604 \\
424 \\
291 \\
296 \\
258 \\
222 \\
99 \\
61 \\
57 \\
44 \\
126 \\
\hline 19,023 \\
\hline $\mathbf{6 , 7 5 9}$ \\
$\mathbf{1 2 , 2 6 4}$
\end{tabular}

\begin{tabular}{rr}
$\begin{array}{c}\text { Obligations } \\
1976\end{array}$ & $\begin{array}{r}1977 \\
\text { estimate }\end{array}$ \\
estimate \\
9,879 & 11,198 \\
3,473 & 3,573 \\
2,812 & 3,282 \\
2,369 & 2,570 \\
628 & 726 \\
483 & 507 \\
340 & 319 \\
332 & 316 \\
305 & 241 \\
247 & 243 \\
108 & 106 \\
97 & 109 \\
62 & 70 \\
65 & 41 \\
138 & 164 \\
\hline $\mathbf{2 1 , 3 3 8}$ & $\mathbf{2 3 , 4 6 5}$ \\
\hline $\mathbf{7 , 1 5 0}$ & $\mathbf{7 , 7 8 2}$ \\
$\mathbf{1 4 , 1 8 8}$ & $\mathbf{1 5 , 6 8 3}$
\end{tabular}

\begin{tabular}{r}
1975 \\
actual \\
9,189 \\
3,181 \\
1,862 \\
2,108 \\
571 \\
418 \\
307 \\
265 \\
207 \\
220 \\
97 \\
54 \\
52 \\
44 \\
124 \\
\hline $\mathbf{1 8 , 6 9 9}$ \\
\hline $\mathbf{6 , 3 5 5}$ \\
$\mathbf{1 2 , 3 4 4}$
\end{tabular}

\begin{tabular}{rr}
$\begin{array}{c}\text { Outlays } \\
1976\end{array}$ & $\begin{array}{r}1977 \\
\text { estimate }\end{array}$ \\
estimate \\
9,468 & 10,762 \\
3,402 & 3,550 \\
2,423 & 3,042 \\
2,366 & 2,512 \\
602 & 647 \\
486 & 510 \\
338 & 304 \\
307 & 310 \\
324 & 298 \\
239 & 233 \\
99 & 100 \\
88 & 103 \\
57 & 67 \\
50 & 44 \\
142 & 156 \\
\hline $\mathbf{2 0 , 3 9 1}$ & $\mathbf{2 2 , 6 3 8}$ \\
\hline $\mathbf{7 , 1 9 2}$ & $=$ \\
$\mathbf{1 3 , 1 9 9}$ & $\mathbf{1 4 , 7 0 9}$ \\
\hline
\end{tabular}


technology, and the likely congressional arguments.

\section{National defence}

Claiming that "we dare not do less", $\mathrm{Mr}$ Ford has proposed a recordbreaking budget for the Department of Defence (DOD), amounting to $\$ 114,000$ million, of which some $\$ 101,000$ million would actually be spent in the 1977 fiscal year. Consequently, military research and development in DOD is set for a whopping budget increase, from about $\$ 9,900$ million to $\$ 11,200$ million. In addition, $\mathrm{Mr}$ Ford has proposed that the Energy Research and Development Administration (ERDA) should spend another $\$ 775$ million on nuclear weapons research. Thus, according to Ford's proposals, military research and development would carry off more than half the total science and technology budget, and its share would actually increase.

Most of that money would be spent on weapons development, with ballistic missile projects receiving highest priority. Defence-related basic research is projected to rise from $\$ 330$ million to $\$ 383$ million. DOD is also under an edict to reduce its civilian staff by some 26,000 which could have repercussions in defence laboratories, and it could also result in more defence work being performed in colleges and universities.

Congress is unlikely to approve an overall defence budget of that size, however, and a major political battle over several weapons programmes should be anticipated.

\section{Energy research and development}

The second area to be favoured with large proposed increases is support of energy research and development programmes, most of which are now clumped in the Energy Research and Development Administration. $\mathrm{Mr}$ Ford's budget includes some $\$ 3,200$ million for direct energy research and development, together with closely related environmental and basic research. That would amount to an increase of nearly $40 \%$. Congress is not likely to quibble about the fact that the budget for such efforts is increasing by leaps and bounds, but it is likely to question the way in which the money is to be divided between nuclear and nonnuclear technologies.

The Ford budget proposes a sharp increase in spending on fission reactor development and related studies on the fuel cycle, from $\$ 852$ million this year to $\$ 1,215$ million next. A good deal of that increase would be swallowed up by the Liquid Metal Fast Breeder Reactor (LMFBR) programme, which alone would receive $\$ 655$ million next year. That heavy emphasis on the
LMFBR is consistent with a recent policy statement by ERDA administrator Dr Robert C. Seamans Jr, who said that after studying the environmental, economic and technological questions surrounding the breeder programme, he has decided that ERDA should proceed rapidly with LMFBR development. The goal is now to have the first commercial LMFBR in operation by 1993.

The other noteworthy increase in the budget for energy research and development is in the thermonuclear programme. Mr Ford has proposed that the fusion programme should receive a total of $\$ 392$ million next year, a massive boost from this year's budget of $\$ 250$ million. A large part of the increase is earmarked for the Tokamak fusion test reactor, a major facility under construction at Princeton University which should be in operation by about 1982. The laser fusion programme is also set for a substantial increase, from $\$ 83.6$ million to $\$ 101$ million.

Large percentage increases have also been proposed for non-nuclear technologies, such as solar energy, development of oil shale, geothermal power, and conversion of coal to liquid and gaseous fuels. But they would continue to receive much less than half the total energy research and development budget.

Congress is likely to question the increased commitment to nuclear energy which the budget entails, but nuclear opponents in Congress probably lack the votes to reduce the nuclear budget substantially. A good deal of noisy skirmishing should be anticipated, however.

\section{Biomedical research}

Once again, the big loser in the federal research and development budget seems to be biomedical research. The situation is, however, greatly complicated by the fact that Congress and the Ford Administration have been unable to agree on the size of the budget for the Department of Health, Education and Welfare (HEW) - of which NIH is a part-for this year, and until they do, the outlook for biomedical research support is very uncertain.

Late last year, Congress passed a bill for HEW which contains very large increases in $\mathrm{Mr}$ Ford's original budget request for NIH in the 1976 fiscal year, which is already well under way. $\mathrm{Mr}$ Ford vetoed the measure, however, because he claimed that it would fuel inflation and instead, he has now proposed that NIH should receive slightly less money this year than it received last. And the budget he has proposed for 1977 would not even restore NIH to the 1975 level if inflation is taken into account. The various budget pro-

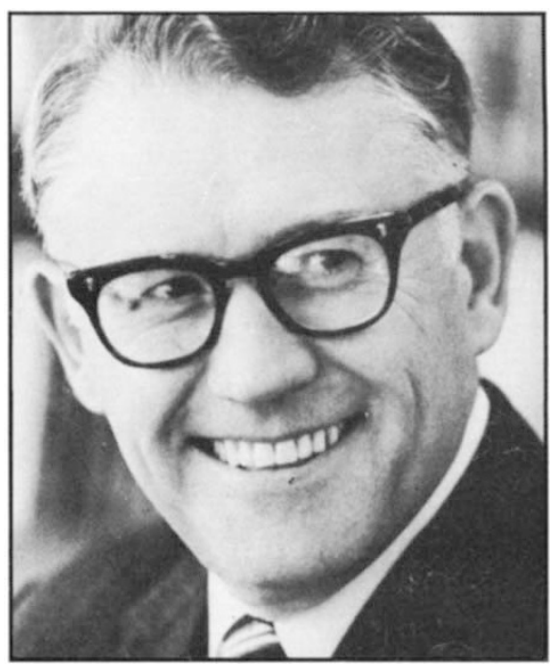

Dr H. Guyford Stever, NSF Director

posals for NIH are shown in Table 2 .

Congress will try this week to override $\mathrm{Mr}$ Ford's veto of the HEW bill. If it is successful, then NIH would receive a hefty budget increase this year. Otherwise, if NIH is funded at the level proposed by Mr Ford, there would be insufficient money available to fund any new projects until next October. In other words, support for new biomedical research would grind completely to a halt. Moreover, NIH budget officials have calculated that $\mathrm{Mr}$ Ford's proposed budget for next year would allow them to fund only $37 \%$ of the grant applications approved by peer review groups. The outcome of Congress's attempt to override the veto is difficult to predict, but the prevailing opinion on Capitol Hill seems to be that it will be successful.

Nevertheless, Mr Ford's budget proposal for 1977 shows a very significant new trend. For the first time in five years, the Administration has suggested that funds for cancer research should be held in check while support for other areas of biomedical research should be allowed to grow. That suggestion follows months of debate about relative priorities in biomedical research, centred on the fact that cancer research funds have grown by $280 \%$ between 1973 and 1975, while NIH's budget for other research has increased by only $20 \%$ in the same period.

It is questionable whether Congress will go along with such a redistribution of funds for biomedical research, but at least the proposal would sharpen discussions of research priorities.

Another problem in NIH's proposed budget is that it contains no provision for increases in NIH staff positions. According to Dr Donald Fredrickson, Director of NIH, that restriction could be especially burdensome because NIH is starting up an entirely new institute devoted to study of the ageing process, and it will be forced to do it without any new people. 
Congress and the Administration should reach some agreement-or at least a stalemate-on NIH's 1976 budget in the next few weeks. The tussle will then begin over the size of the budget for next year, all of which makes for extremely difficult planning not only at NIH but also in the universities, which now receive about $\$ 1,300$ million a year in grants and contracts from NIH.

\section{The National Science Foundation}

The bulk of federal funds for basic research come from the National Science Foundation (NSF). Its budget is therefore closely watched in the scientific community as a barometer of federal support for basic research. About $87 \%$ of NSF's money is spent on grants to scientists in colleges and universities.

The budget proposed for NSF would result in a total increase of about $11 \%$, reaching $\$ 812$ million. Within that total, NSF's basic research programmes would grow by nearly $20 \%$, while its applied research and education support would either decrease or remain constant. According to Dr Stever, the "specific aim" of the proposed increases "is to counteract the gradual decrease in federal support for basic research which has declined by about $23 \%$ in terms of constant dollars since 1968 ".

The proposed increases in research support would be applied more or less evenly throughout the sciences. No new large projects are planned, but the budget contains sufficient money to continue construction on schedule of the very large array telescope system which is being built in New Mexico.
Usually, NSF's budget attracts little attention in Congress, and aside from minor tinkering by the appropriations committees, the Foundation receives close to the amount of money requested. But last year NSF came in for very heavy criticism on Capitol Hill from Congressmen and Senators who believed that it was either supporting trivial research or that it was developing morally unacceptable school science courses. Consequently, Congress cut NSF's budget for this year, and arranged that basic research bore the brunt of the reductions. Close scrutiny of NSF's programmes can be expected again this year, and Stever warned last week that if the decline in basic research support is to be halted, "Congress must rally round this budget".

\section{Space science}

Once again, the National Aeronautics and Space Administration (NASA) has been cut back and space science has been squeezed especially hard. Dr James Fletcher, the Administrator of NASA, said last week that the proposals for NASA mean that 1977 "will be another year of tight constraints, minimal budgets and limited new activities".

The chief problem is that NASA's total budget is being held approximately constant, while expenditures on the space shuttle are increasing rapidly. The net result is that the shuttle is soaking up a growing share of the Agency's budget, leaving little to spare for space science. Next year, for example, out of a total of some $\$ 3,676$ million proposed for NASA, the space shuttle will account for $\$ 1,288$ million.

The effects of the squeeze will be particularly severe in the budget for the Office of Space Science, which is set to shrink from $\$ 417$ to $\$ 379$ million. Only one major new start has been proposed for next year-a so-called solar maximum mission, a spacecraft which will study solar flares and other phenomena during the period of peak solar activity in 1979-80. The chief casualty is the Large Space Telescope (LST), an optical telescope which NASA hopes to fly on an early shuttle mission in the early 1980s. The LST has been accorded top priority by the Space Science Board of the National Academy of Sciences, and NASA was hoping to begin developing it this year. A start has now been deferred, however, until at least 1978.

Another high priority space science mission which will have to wait for at least another year is the proposed mission to send an orbiter and probe to Jupiter in 1981. Again, there is no money in the budget for that mission, but NASA officials are hoping to make a start in 1978. But one planned venture has been scrapped entirelythe proposal to send a Mariner spacecraft to Jupiter and then on to Uranus. Because there is no money in NASA's budget to start work on that mission next year, the opportunity to make use of a rare alignment of the outer planets to send a spacecraft past Jupiter and on to Uranus will be lost. NASA officials are hoping, however, to reprogramme an already-approved spacecraft due to be launched next year, so that it will fly close to Uranus in 1985 after it swings past Saturn.

In past years, Congress has not made many substantial changes to NASA's space science budget, and there is no reason to expect any difference this year.

Table 2 National Institutes of Health (in $\$$ thousand)

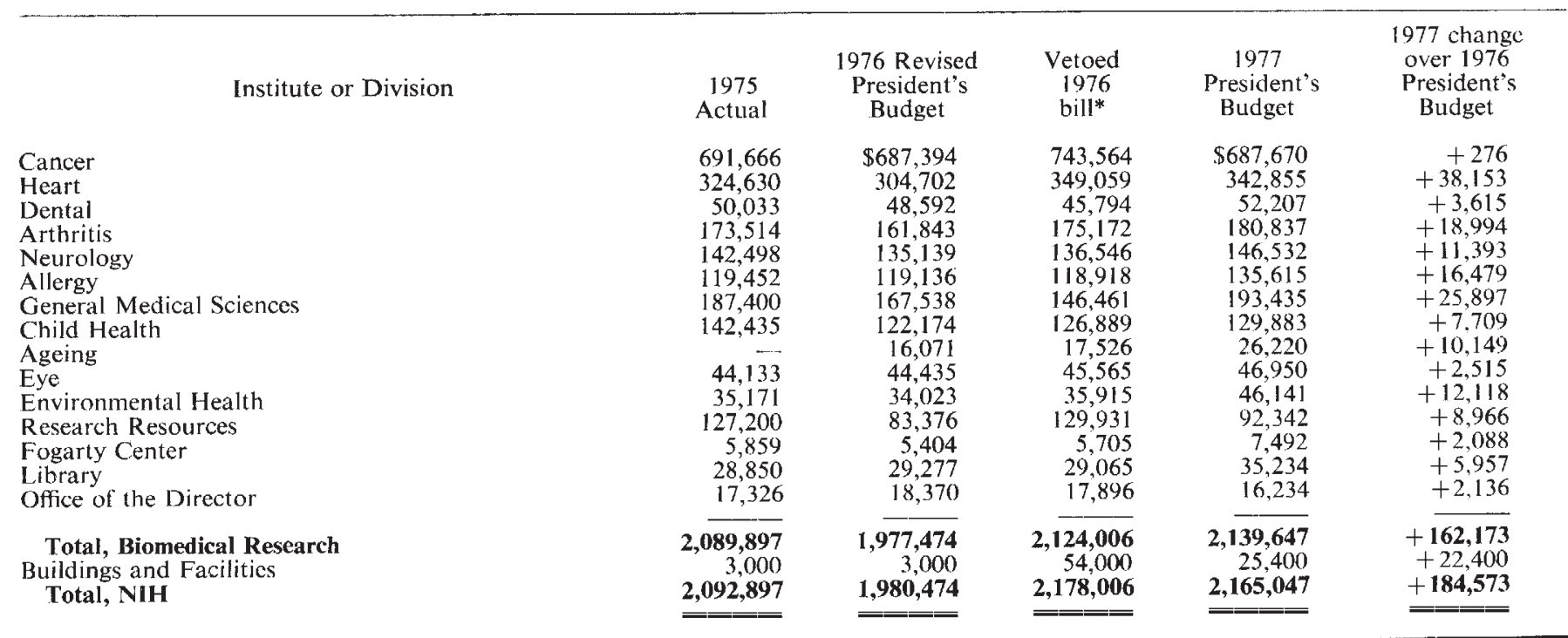

* Does not include money for training grants, which is included in other columns. Congress has voted a separate budget of $\$ 124$ millions for biomedical training in 1976, which would bring the total for biomedical research in the vetoed bill to $\$ 2,300$ million. 